OPEN ACCESS

Edited by:

Yuri Zillberter,

INSERM U1106 Institut de

Neurosciences des Systèmes, France

Reviewed by:

Kristin Eckel-Mahan,

School of Medicine, University of

Texas Health Science Center at

Houston, United States

Olga Golubnitschaja,

University of Bonn, Germany

${ }^{*}$ Correspondence:

Thomas R. Wood

tommyrw@uw.edu

Specialty section

This article was submitted to

Neuroenergetics, Nutrition and Brain

Health,

a section of the journa

Frontiers in Nutrition

Received: 26 November 2019

Accepted: 22 June 2020

Published: 07 August 2020

Citation:

Potter GDM and Wood TR (2020) The Future of Shift Work: Circadian Biology Meets Personalised Medicine and

Behavioural Science.

Front. Nutr. 7:116

doi: 10.3389/fnut.2020.00116

\section{The Future of Shift Work: Circadian Biology Meets Personalised Medicine and Behavioural Science}

\author{
Gregory D. M. Potter ${ }^{1}$ and Thomas R. Wood ${ }^{2,3 *}$ \\ ${ }^{1}$ Independent Researcher, London, United Kingdom, ${ }^{2}$ Division of Neonatology, Department of Pediatrics, University of \\ Washington, Seattle, WA, United States, ${ }^{3}$ Division of Human Health, Performance and Resilience, Institute for Human and \\ Machine Cognition, Pensacola, FL, United States
}

Shift work is commonplace in modern societies, and shift workers are predisposed to the development of numerous chronic diseases. Disruptions to the circadian systems of shift workers are considered important contributors to the biological dysfunction these people frequently experience. Because of this, understanding how to alter shift work and zeitgeber (time cue) schedules to enhance circadian system function is likely to be key to improving the health of shift workers. While light exposure is the most important zeitgeber for the central clock in the circadian system, diet and exercise are plausible zeitgebers for circadian clocks in many tissues. We know little about how different zeitgebers interact and how to tailor zeitgeber schedules to the needs of individuals; however, in this review we share some guidelines to help shift workers adapt to their work schedules based on our current understanding of circadian biology. We focus in particular on the importance of diet timing and composition. Going forward, developments in phenotyping and "envirotyping" methods may be important to understanding how to optimise shift work. Non-invasive, multimodal, comprehensive phenotyping using multiple sources of time-stamped data may yield insights that are critical to the care of shift workers. Finally, the impact of these advances will be reduced without modifications to work environments to make it easier for shift workers to engage in behaviours conducive to their health. Integrating findings from behavioural science and ergonomics may help shift workers make healthier choices, thereby amplifying the beneficial effects of improved lifestyle prescriptions for these people.

Keywords: chronomedicine, chrononutrition, chronotherapy, circadian disruption, light exposure, physical activity, shift work, time-restricted eating

\section{INTRODUCTION}

Simplistically, our species once lived by two "clocks." One of these clocks is the environmental clock, which generates roughly 24-h changes in the light/dark (LD) cycle. The other clock is the endogenous biological clock, which among other rhythms generates roughly 24-h (circadian) rhythms in biological outputs such as the sleep/wake cycle. Prior to the introduction of artificial light at night, these two clocks were probably tightly synchronised $(1,2)$. Following industrialisation, however, people can more easily work outside of conventional daytime hours, and $15-20 \%$ of the working population now work shifts (3). The burden of shift work is striking: Shift workers are not only at increased risk of accidents (4), they are also disposed 
to developing numerous diseases, including certain cancers, coronary heart disease, stroke, and type-two diabetes (5). Few studies have explored whether shift work makes individuals prone to neurodegenerative diseases $(6,7)$, but shift work frequently disrupts biological rhythms and sleep, and such disturbances propagate a slew of pathobiological changes that contribute to neurodegeneration (8). While at the time of writing little is known about the effects of the 2019 novel coronavirus disease (COVID-19) pandemic on the lives of many shift workers, we would be remiss not to mention that many healthcare professionals at the frontlines of the outbreak are currently working long shifts in conditions that dispose them to developing COVID-19 (9). Many of the chronic conditions associated with shift work are also associated with greater risk of poor outcomes in those with COVID-19 as well as other coronavirus and influenza infections (10-17). As shift workers often work jobs considered essential during the COVID19 pandemic, improving the health of shift workers should become a key part of current and future pandemic preparedness. Importantly, however, at present there is no strong evidence that people fully adapt to shift work (18). And considering that the unconventional schedules of shift workers also interrupt the lives of cohabiting non-shift workers, the burden of shift work is greater still. The purpose of this manuscript is therefore to summarise some ways by which we might be able to reduce this burden.

\section{OPTIMISING SHIFT WORK SCHEDULES}

Optimising shift work schedules is fundamental to the health and productivity of shift workers. In general, it appears that most shift workers tolerate rapid, forward (clockwise) rotation schedules best (5). To support worker wellbeing, these shifts should each last no longer than $10 \mathrm{~h}$, have at least $11 \mathrm{~h}$ of recovery between them, and amount to no more than $60 \mathrm{~h}$ of work per week (5). To hone shift work schedules for individual workers, workers may benefit from having some control of their schedules. This autonomy helps account for differences between people in nonwork responsibilities, tolerance to shift work, and commuting to and from work.

Chronotype is another tailoring variable that is particularly germane to optimising shift work schedules. Chronotype is defined as interindividual differences in the phenotypic expression of behavioural outputs regulated by the circadian system (19), the most conspicuous of which is the timing of the sleep/wake cycle, and in industrialised societies there exist large differences between individuals in their chronotypes (20). Chronotype appears to modify the association between shift work schedules and risk of health problems (21), such that the health of early chronotypes may be especially negatively affected by working night shifts (22), whereas late chronotypes find working morning shifts particularly problematic (23). While it is not clear precisely why this interaction exists, shift workers who have closer alignment between their chronotypes and their work schedules appear to have more robust melatonin rhythms than their fellow shift workers, suggesting that they have better circadian system function (24). Shift workers who have chronotypes that are better matched to their work schedules may also sleep better (23), and it is increasingly clear that circadian system and sleep health are essential to perhaps all facets of human health $(25,26)$.

\section{OPTIMISING ZEITGEBER SCHEDULES}

The period of each individual's circadian system is one determinant of his or her chronotype. In the absence of time cues (zeitgebers), the free-running period of the human circadian system is slightly longer than $24 \mathrm{~h}$, on average (27). The circadian system therefore needs to be synchronised (entrained) each day with the 24-h day, and shift work complicates this process.

\section{Exposure to Light}

Retinal light exposure is generally regarded as the most important stimulus in entraining the human circadian system (28), and changes in patterns of light exposure can rapidly and substantially shift circadian system timing (phase). This is especially true of short-wavelength light, which most potently suppresses melatonin synthesis (29). Exposure to such light in the biological morning tends to advance circadian phase, whereas exposure to such light in the late biological evening tends to delay circadian phase. The implication of this is that it is possible to bolster how well-shift workers adapt to work schedules through timely use of means to increase exposure to high-intensity, shortwavelength light at specific times of day (e.g., by using lighttherapy lamps) and means to reduce exposure to such light at specific times of day (e.g., "blue-blocking" glasses and blue-light filtering apps on electronic devices). While not all studies that have used interventions to modify exposure to light in shift workers have proven beneficial, this inconsistency likely reflects marked heterogeneity in the methods used by researchers (30), as well as large variation between people in how they respond to light (31).

\section{Melatonin}

During darkness, retinal photoreceptors no longer register exposure to light, relaying this to the central clock in the circadian system (the suprachiasmatic nucleus), which in turn signals the pineal gland to synthesise melatonin. Melatonin therefore acts as an endogenous marker of darkness, agonising its receptors in cells in numerous tissues to signal them to fulfil time-ofday-specific functions. Simplistically, when the concentration of melatonin in the blood surpasses a certain threshold in humans who are melatonin-proficient, it is the biological night-time. Conversely, when the concentration of melatonin is below this threshold, it is the biological daytime.

Melatonin supplementation can shift the phase of the circadian system (32). Melatonin ingestion in the late biological afternoon tends to advance circadian phase, while ingestion in the early biological morning tends to delay it. Melatonin is therefore a chronobiotic - an agent that can modify circadian phase. When timed appropriately, light exposure and melatonin ingestion additively shift circadian phase (33). 


\section{Exercise}

A growing body of evidence also shows that exercise can shift circadian phase. Early research demonstrated that $15 \mathrm{~min}$ of cycling exercise each hour of night shifts helped workers adjust their circadian systems to a 9-h delay in bedtime (34). More recent work has begun to clarify the precise nature of the relationship between exercise and circadian phase, showing that treadmill exercise done in the early biological morning or early biological afternoon advances circadian phase, whereas the same exercise done in the biological evening delays it (35). This relationship is therefore similar to how timing of exposure to light affects circadian phase, and timely exposure to both light and exercise can also additively shift circadian phase (36).

\section{Nutrition}

The influence of timing of food availability on patterns of activity in rats was documented as early as a century ago (37), and numerous studies of such "food anticipatory activity" have since implicated nutrition as an influence on circadian system timing. Whereas the LD cycle is the primary zeitgeber for the suprachiasmatic nucleus, some scientists have hypothesised that the eating/fasting cycle may be the primary time cue for some peripheral clocks in the circadian system. We now know that changing the timing of food consumption rapidly alters the timing of gene transcription in peripheral clocks in mice, for example (38). Recent work has shown that this may be true of humans too, for changing meal timing independently shifts the expression of some genes in peripheral tissues as well as the timing of the blood glucose rhythm, without changing the phase of the melatonin rhythm (39). We acknowledge, however, that lack of control of variables such as LD cycles in most studies of the effects of nutrition on the human circadian system mean that this is arguably the only study of people that fulfils at least one of the criteria for diet to be classified as a zeitgeber (40). It could be that entrainment to LD cycles largely nullifies any zeitgeber effects of nutrition (41).

Summarising the above, it is plausible that carefully timed exposure to light, melatonin ingestion, and exercise may result in additive shifts in the phase of the suprachiasmatic nucleus. As eating/fasting cycles appear to affect the phases of some peripheral circadian clocks, we anticipate that coordinated changes in all of these variables could be used to expedite adaptation to new shift work schedules. If one could estimate shift workers' circadian phases in real time and model how subsequent changes in zeitgeber schedules would influence their circadian systems, one could develop tools that use this information to expedite adaptation to shift schedule changes by providing personalised guidance and perhaps even individual-level changes in exposure to light. This may be a particularly fruitful topic for further study.

\section{CHRONONUTRITION: THE IMPORTANCE OF DIET TIMING}

While it is plausible that one could change nutrient timing to accelerate adaptation to new shift work schedules, in many instances shift workers do not seek to fully adjust to their new shifts. This raises the question of whether workers undergoing transient changes in work schedules should adjust their diets accordingly. However, it is also crucial to consider contextual factors that influence when shift workers eat and drink. Work schedules, time constraints, timing of breaks within shifts, family commitments, and prioritising behaviours such as sleep over meals all influence diet timing in shift workers, leading to erratic diet timing patterns in these people (42). Diet timing irregularities are also affected by cultural factors (e.g., Ramadan) and the nature of some jobs (e.g., many on-call workers have especially unpredictable work schedules). Temporarily putting these complexities to one side, controlled experiments have begun to explore the effects of diet timing during pre-clinical and clinical simulations of shift work. Table 1 summarises our dietary and supplementation suggestions for shift workers based on our interpretation of the current literature.

\section{Diet Timing in Shift Workers}

Beginning with preclinical research, studies of mice have shown that restricting food access to the dark period (the active phase for these nocturnal animals) may protect against the obesogenic effects of repeated 6-h advances in the LD cycle (48). In addition, restricting food access to the active phase may also accelerate adaptation of circadian rhythms in core body temperature and locomotor activity to repeated 12 -h changes in LD cycles (49). These findings imply that people would better cope with rotating shift work if they fixed their eating to the daytime, which is somewhat counterintuitive given that fixing eating time during shifting LD cycles might be expected to uncouple circadian rhythms between the suprachiasmatic nucleus and peripheral clocks. It is, however, intuitive that restricting food access to the active phase may be preferable to restricting it to the rest phase, and findings from initial research on humans support this contention.

Among healthy young men undergoing simulated night shift work for 4 days, those who confined their consumption of calorie-containing foods and drinks (i.e., the caloric period) to between breakfast at 07:00 and dinner at 19:00 had superior postbreakfast glucose tolerance after the intervention compared to men who had dinner at 19:00, a meal at 01:30, and breakfast at 07:00 (50). The group that restricted food intake to the daytime also had superior overnight cognitive function (51). This is especially salient given that many shift workers redistribute their energy intakes into the night when working shifts (52). Additional studies using larger sample sizes and investigating the effects of diet composition on a range of round-the-clock postprandial responses will be instructive.

\section{Time-Restricted Eating: Findings From Non-shift Workers}

Studies of adults undergoing time-restricted eating (TRE) also indicate that optimising nutrient timing is likely to be important to cardiometabolic health, although the participants in these studies have generally not been shift workers. We arbitrarily define TRE as consumption of all calorie-containing items within a period of $12 \mathrm{~h}$ or less each day. Conversely, we define 
TABLE 1 | Dietary and supplementation suggestions for shift workers.

The caloric period

Distribution of macronutrient intakes within the caloric period

Sequence of macronutrient intakes within dietary events Snacking outside the caloric period

Caffeine

Creatine

Melatonin
Workers should restrict consumption of all items containing $>5$ calories to a 6 - to 12 -h period each day, when possible. They should keep the timing of this period as regular as is feasible from day to day. Workers should self-select the timing of this period, and the ideal time for this period may be relatively early in each worker's biological daytime. We therefore recommend that workers select a caloric period that finishes at least $3 \mathrm{~h}$ before their most common bedtime.

Workers who have poor cardiometabolic health should aim to consume at least half of daily energy intake in the first half of the caloric period (e.g., by increasing the size of breakfast and reducing the size of dinner). This is less relevant to people who exercise in the second half of their caloric period.

Workers should also aim to evenly divide their protein intakes between dietary events. As a starting point, we recommend that workers aim to consume $\sim 0.4 \mathrm{~g}$ protein per $\mathrm{kg}$ bodyweight at each of 3 to 4 evenly-spaced dietary events each day (43).

Workers who have poor glycaemic control should consume carbohydrate-rich foods last at dietary events, when practical (e.g., consuming fibre- and protein-rich salads before meals or eating meat and vegetable foods before carbohydrate-rich foods).

When workers feel it would be beneficial to snack outside of the caloric period (e.g., to abate hunger and/or support alertness), they may benefit from consuming relatively small (i.e., 10-20\% daily caloric intake), minimally processed, micronutrient-dense, satiating, easy to digest, convenient snacks. We hypothesise that relatively high-protein, low carbohydrate snacks are ideal at these times (e.g. snack items may include boiled eggs, dairy products, minimally-processed fish jerky or meat jerky, high-protein drinks, nuts, whole vegetables, and/or low-sugar whole fruits such as berries).

If their goal is to support cognitive function during shifts, workers may benefit from individual doses of 1-4 mg caffeine per kg bodyweight, favouring the upper end of this range if short on sleep (44). Repeated doses of caffeine every $2 \mathrm{~h}$ or so may maximally support cognitive function during extended wakefulness (45). As consuming caffeine as gum leads to faster absorption than consuming caffeine as capsules (46), caffeinated gum may be particularly helpful if the goal is to affect cognition as quickly as possible. Since mistimed caffeine intake impairs sleep, workers should also stop consuming caffeine at least $7 \mathrm{~h}$ before the main sleep period, if possible (47). Individuals differ remarkably in their responses to caffeine ingestion, so they should moderate their intakes according to their individual responses. As a starting point, we recommend consuming no more than $6 \mathrm{mg}$ caffeine per kg bodyweight per $24 \mathrm{~h}$.

Creatine monohydrate consumption may help shift workers cope with sleep loss. During periods of insufficient sleep, we tentatively recommend that shift workers consume $0.1 \mathrm{~g}$ creatine monohydrate per kg bodyweight per day. Because of its potential alertness-boosting properties, we speculate that the ideal time to consume creatine is with the first meal of each day.

Well-timed melatonin use may help some shift workers adapt to new work schedules and sleep better during these transitions. We tentatively recommend that workers consume a dose of $0.3-5 \mathrm{mg}$ melatonin at these times, beginning with a dose at the low end of this range and adjusting the dose according to responses. Because of its potent chronobiotic properties, the optimal timing of melatonin ingestion depends on variables such as the individual's circadian phenotype and work schedule. We therefore do not offer guidance related to melatonin ingestion timing. intermittent fasting as periodic abstinence from consumption of any calories for at least $24 \mathrm{~h}$.

Skipping breakfast is one way to implement TRE, and doing so leads to late TRE. While breakfast-skipping is a controversial topic, epidemiologic studies have tended to associate breakfast consumption with lower risk of developing cardiometabolic diseases such as heart disease and type-two diabetes $(53,54)$. However, controlled studies have not shown large effects of skipping breakfast on cardiometabolic health (55). For example, lean adults who skipped breakfast for 6 weeks inadvertently decreased their daily energy intakes, but this change was compensated by reductions in physical activity energy expenditure, resulting in no changes in energy balance or body composition (56). Skipping breakfast did not affect most measures of cardiometabolic health - the only noteworthy difference between groups was that afternoon glycaemic variability was higher in adults who skipped breakfast. A subsequent study implemented the same intervention but only included obese adults (57). In this study, participants in the breakfast-skipping group expended less energy in the morning, but they did not burn fewer calories over the entire day. Daily energy intake was similar in breakfast-skippers and breakfast eaters, and both groups gained weight during the study. People who skipped breakfast did have higher insulinaemic responses to an oral glucose tolerance test, however. These two rigorous studies show that skipping breakfast minimally affects energy balance but may negatively affect glycaemic regulation and some of its determinants. As sleep timing did not differ between groups, breakfast skipping led to a form of late TRE, so these studies imply that late TRE may not be optimal for some aspects of cardiometabolic health.

Skipping breakfast imposes a relatively late caloric period, and an alternative is to shorten the caloric period by way of skipping dinner or having an early dinner. Several recent carefully controlled experiments have shown that such early TRE may exert numerous positive effects on health. The first of these experiments reported that compared with a $\sim 12$-h daily caloric period for 5 weeks, 5 weeks of early TRE $(\sim 6$-h daily caloric period, finished by 15:00) improved insulin sensitivity, blood pressure, appetite regulation, and a marker of oxidative stress in men who have prediabetes (58). The same group of scientists recently reported that in overweight adults, just 4 days of early TRE reduced mean 24-h blood glucose levels and improved metabolic flexibility, among other benefits $(59,60)$.

These experiments did not compare early TRE to later TRE while keeping the caloric period fixed, however, and to our knowledge, only one study has done this to date (61). The study in question showed that 7 days of both early (08:00 to 
17:00) and late (12:00 to 21:00) TRE improved oral glucose tolerance in men at high risk of developing type-two diabetes, although only early TRE lowered fasting glucose, suggest a small advantage of early TRE (61). While this hypothesis needs careful testing, we believe that early TRE may also enhance diet composition by reducing intakes of foods and drinks commonly consumed in the evening, such as processed snacks and alcohol.

Together, these studies support the superiority of relatively early TRE in adults who have poor cardiometabolic health. However, non-self-selected TRE schedules may interfere with some social activities and be difficult to adhere to in the context of work schedules and family commitments $(62,63)$. Letting people self-select their TRE periods helps mitigate these undesirable consequences. Indeed, 12 weeks of self-selected TRE minimised these issues in adults with metabolic syndrome, also reducing daily energy intake and potently improving numerous aspects of cardiometabolic health including bodyweight, waist circumference, and blood pressure (64). Moreover, TRE led to more regular diet timing, which may independently be beneficial for cardiometabolic health (65). Interestingly, TRE also improved sleep timing regularity and increased how often participants selfreported restorative sleep. However, this study was an unblinded, single-arm study with only 19 participants included in the data analysis (64).

Based on existing studies, TRE appears to be a safe strategy that is likely to reduce energy intake, which would be especially beneficial for people who have unavoidably sedentary lifestyles. We hypothesise that fixing the timing of each worker's caloric period within regular hours each day supports metabolic health, and it is plausible that this may be especially important in workers who are subject to unpredictable changes in zeitgebers such as LD cycles (e.g., emergency service workers). We further speculate that each worker's biological daytime is the optimal time at which to fix the individual's caloric period, but self-selection of TRE schedules will help people adhere to TRE and avoid undesirable effects on social and family life. This said, scheduling TRE as early as is practical may maximise the beneficial cardiometabolic effects of TRE.

\section{Distribution of Energy and Macronutrient Intakes Within the Caloric Period: Findings From Non-shift Workers}

While a detailed discussion of this subject is beyond the scope of this review, several recent controlled studies have shown that when daily energy intake is fixed, the distributions of energy and macronutrient intakes within the caloric period strongly influence cardiometabolic health. For example, one study divided overweight and obese women into two groups that consumed isocaloric weight loss diets for 12 weeks (66). One group consumed half of their daily energy intakes at breakfast, the other group consumed half at dinner. The group that consumed half at breakfast lost more than twice as much bodyweight, more than twice as many centimetres off their waists, and had greater improvements in oral glucose tolerance. Subsequent work by the same scientists demonstrated that when energy intake is controlled, concentrating energy and carbohydrate intakes early in the day leads to enhanced appetite regulation, weight loss, and dramatic improvements in glycaemic control in adults with type-2 diabetes (67). This builds on research demonstrating that having carbohydrate-rich meals early in the day reduces 24-h glycaemia in adults with impaired fasting glucose and/or impaired glucose tolerance (68).

While these studies highlight the advantages of concentrating energy and carbohydrate intakes relatively early in the caloric period, we note that that intelligent inclusion of physical activity leads to acute improvements in postprandial responses to dietary events such that relatively high energy and carbohydrate intakes late in the biological day may not be so problematic if they bookend exercise (69). And staying on the subject of exercise, there is tentative evidence that distribution of daily protein intake affects skeletal muscle protein synthetic responses to resistance training (70). As muscle protein synthesis is the main determinant of muscle protein balance, it is reasonable to assume that evenly dividing and spacing protein intakes between 3 and 4 daily dietary events may help maximise fat-free mass, a key determinant of cardiometabolic health (43).

\section{Sequence of Macronutrient Intakes Within Dietary Events: Findings From Non-shift Workers}

We would be negligent to not mention that the sequence of macronutrient intakes within dietary events may also meaningfully affect postprandial responses. Several studies by one research group have shown that consuming carbohydrate last at a given dietary event (e.g., a full meal) dramatically reduces postprandial glycaemia and insulinaemia in adults who have prediabetes or type-two diabetes (71-73). Shift workers who have poor glycaemic control may hence benefit from consuming carbohydrate-rich foods last at dietary events, when practical.

\section{Snacking in Shift Workers}

Most shift workers snack during night shifts. The problem is that night shifts often occur during the workers' biological nighttimes, and digestive and metabolic responses to dietary events are impaired during the biological night (74). As highlighted earlier, eating and/or drinking during the biological night-time may disrupt peripheral clocks. If workers snack during night shifts, it is therefore important to minimise energy intake and select dietary choices that lead to favourable postprandial responses. These snacks should also be convenient, minimally processed, micronutrient-dense, satiating, easy to digest, and minimally perishable, when applicable.

Preliminary research has shown that when 24-h energy and macronutrient intakes are controlled during simulated night shifts, a small snack (containing $10 \%$ of daily energy intake) may support cognitive function and performance in simulated driving compared with no snacking or a larger meal containing $30 \%$ of daily energy intake (75). In this instance, the small snack also reduced hunger to a comparable extent to the meal, without leading to significant digestive discomfort (76). Compared to large night-time snacks, small night-time snacks may also be 
better for metabolic health. Glycaemic control is relatively easy to measure and predictive of many health outcomes, and some researchers have therefore focused on the effects of nocturnal snacking on glycaemic control. Compared with a small midnight snack ( $\sim 200$ calories), a large midnight snack ( $\sim 500$ calories) impaired postprandial glycaemic responses at a subsequent breakfast at 08:30 during simulated shift work (77). Research such as this is informative, but we again need additional studies of workers in which the effects of dietary changes on metabolic parameters are measured around the clock.

\section{CHRONONUTRITION: THE IMPORTANCE OF DIET COMPOSITION}

Shift workers are not only apt to consume foods and drinks at suboptimal circadian phases, the quality of shift workers' diets is often worse than that of day workers too. Many shift workers report consuming few fruits and vegetables while also consuming a variety of processed foods at work, such as biscuits, cakes, chocolates, pastries, sandwiches, and fried foods (42). As diet composition affects metabolic health and cognitive function, it is important to help these people make better dietary choices. One way by which diet composition influences health is via effects on the circadian clockwork, and the ketogenic diet (KD) exemplifies this. There has been a resurgence in interest in the KD of late, and while some believe that the restrictive nature of the $\mathrm{KD}$ is a barrier to its widespread implementation, certain properties of the KD make it an appealing option for some shift workers who are able to adhere to it.

\section{The Ketogenic Diet}

Studies of mice have shown that the KD has chronobiotic actions on the clocks in multiple peripheral tissues, including the brain, gut, and liver (78-80). Interestingly, Tognini and colleagues found that a KD induced distinct changes in the liver and gut clocks in mice. Compared to a control diet, consumption of a KD produced greater amplitudes of clock gene transcription and their downstream products in the liver, as well as inducing 24-h oscillations in the transcription of many genes in the gut (78). As disruption of the gut clock is associated with increased intestinal inflammation and permeability, as well as endotoxaemia (78, 81 ), if translatable to humans these results suggest that shift workers who follow a KD may protect themselves against some of the adverse consequences of consuming calories at suboptimal circadian phases.

More generally, both the $\mathrm{KD}$ and less severe carbohydrate restriction may reduce some negative effects of shift work on metabolic health. Shift workers are at an increased risk of impaired glucose tolerance and type-two diabetes, and restricting carbohydrate intake is likely to reduce fasting and postprandial glycaemia, both of which are precursory to numerous chronic diseases (e.g., some cardiovascular diseases, certain cancers, and dementia) (82-87). Preliminary evidence has shown that a multicomponent lifestyle intervention centred on the KD may also improve subjective sleep quality in adults who have poor glycaemic control (88), suggesting that sleep enhancement may mediate some of the reported benefits of the KD.

In preclinical studies, ketone bodies themselves have been found to have pleiotropic beneficial physiological effects, including modulation of inflammation, tissue-specific suppression of mTOR signalling, and increased production of brain-derived neurotrophic factor (89-91). If translatable to humans, these systemic effects of ketone bodies imply that long-term consumption of a $\mathrm{KD}$ could reduce risk of certain cancers and neurodegenerative diseases such as Alzheimer's in shift workers, particularly those that are already at increased risk $(92,93)$. Increased production of ketone bodies may also account for some benefits of fasting and TRE. For example, early TRE led to greater morning beta-hydroxybutyrate levels compared to a 12-h caloric period (59). However, there have not yet been any clinical trials of the $\mathrm{KD}$ in shift workers, and it will be interesting to explore how the combination of the $\mathrm{KD}$ and TRE and/or intermittent fasting interact to affect ketosis, metabolic regulation, and circadian biology in these people.

\section{Other Dietary Chronobiotics}

In addition to effects of dietary patterns on the circadian system, specific dietary compounds have chronobiotic actions. A multitude of dietary compounds affects the circadian system and sleep $(94,95)$, and it is beyond the scope of this article to discuss them all. We therefore focus on some of those that we anticipate may be practical and beneficial for shift workers. In the future, screens for novel chronobiotics and hypnotics may yield compounds that support the health and performance of these workers (96). Identifying agents that counter decrements in health and cognitive function incited by sleep disruption would also benefit shift workers.

\section{Caffeine}

Largely by antagonising adenosine receptors, consumption of caffeine can improve alertness, attention, reaction time, and mood, as well as physical performance in tests of endurance, strength, and power (44). Studies of caffeine consumption by shift workers have consistently shown beneficial effects on multiple aspects of cognitive function, although whether this results in improved safety is not clear (97). The trade-off is that caffeine consumption tends to prolong sleep latency, reduce slow-wave activity during sleep (which is important to numerous restorative processes), shorten sleep duration, fragment sleep, and worsen subjective sleep quality (98). Consumed late in the day as coffee, caffeine also delays circadian phase (99). Thus it is clear that while judicious caffeine intake can be used to help shift workers perform at work - especially when sleepy - mistimed caffeine intake may strongly degrade sleep, which is noteworthy given that many of the adverse consequences of shift work appear to relate to its detrimental effects on sleep (5). It therefore seems prudent to recommend that shift workers generally stop consuming caffeine several hours before their main sleep period (more specific guidance on caffeine intake is provided in Table 1). 


\section{Creatine Monohydrate}

Antagonising adenosine receptors is one way to reduce the accumulation of pressure to sleep (sleep homeostasis), but another is to bolster the phosphorylation of adenosine. Creatine (creatine monohydrate, specifically), a safe and inexpensive dietary supplement that increases brain phosphocreatine stores, countering the accumulation of extracellular adenosine in the brain during extended wakefulness. A study of rats showed that adding creatine to the rats' chow for 4 weeks reduced the duration and slow-wave activity of the rats' sleep (100). We do not currently know the effects of creatine supplementation on sleep in humans, however. Notably, while shorter sleep would generally be expected to impair health and performance, creatine supplementation has repeatedly been shown to enhance these variables in humans. Creatine supplementation routinely improves performance in - and adaptations to - many exercise tasks, and creatine has a number of therapeutic actions, including neuroprotective properties (101).

Interestingly, creatine supplementation may also acutely help protect against the deleterious consequences of sleep loss. After sleep loss, creatine supplementation seems to offset deterioration in executive function, mood, reaction time, balance, and other motor skills (102-104). Although we expect creatine supplementation to be a useful strategy to help but this people cope with shift work, we are not aware of any research on this topic. We also note that there is some evidence that concurrent consumption of caffeine may reduce some of the ergogenic effects of creatine on physical performance (105), and additional studies are needed to better identify how the two compounds interact.

\section{Dietary Amino Acids}

Several dietary amino acids may influence circadian rhythms and sleep. For instance, L-tryptophan is a precursor to melatonin that researchers have studied with respect to circadian rhythms and sleep. As an example, there appears to be a temporal relationship between consumption of L-tryptophan in breast milk and infant urinary excretion of 6-sulfatoxymelatonin, the primary metabolite of melatonin (106). Furthermore, infants fed L-tryptophan-enriched night-time formula seem to experience more consolidated sleep/wake patterns (107). Many studies of adults have also shown that $\sim 2 \mathrm{~g}$ L-tryptophan each day enhances some sleep parameters, although it is not a potent hypnotic (108). To our knowledge, there are no rigorously controlled studies demonstrating that L-tryptophan affects circadian phase, however.

Overall, there has been little research on whether amino acids affect circadian system parameters. In a screen of whether amino acids affect light-induced shifts in the phase of wheel running activity in mice, L-serine increased the magnitude of phase shifts by $86 \%$. This effect seems to translate to humans, as adults who consumed L-serine before bedtime experienced a greater advance in circadian phase in response to bright light exposure (109). Another study reported that 1 week of Lornithine supplementation delayed the plasma melatonin rhythm by $15 \mathrm{~min}$ (110). However, LD cycles and meal timing were not fully controlled in these studies. Interestingly, there is also preliminary evidence that regular L-ornithine supplementation
(400 mg per day) may enhance sleep quality during stressful periods $(111,112)$.

L-glycine may too affect sleep. Consuming $3 \mathrm{~g}$ L-glycine an hour before bedtime appears to shorten sleep latency, increase sleep efficiency, and reduce daytime sleepiness in healthy adults, effects that appear to be mediated via the suprachiasmatic nucleus $(113,114)$. Such supplementation also seems to diminish daytime fatigue and boost vigilance during sleep restriction (115), implying that L-glycine may both enhance sleep and the ability to cope with sleep loss. Given that L-glycine is safe, inexpensive, and may confer other health benefits (116), night shift workers could gain from supplementing with this amino acid. At present, however, there has been little research on effects of this amino acid on sleep.

In summary, it is plausible that supplementing with certain amino acids may help shift workers adapt more quickly to changes in their shifts and/or sleep better, but this is based on few studies that did not control zeitgeber cycles or explore whether the circadian timing of amino acid ingestion interacts with the circadian timing of light exposure. Going forward, it will be important to address these limitations. It will also be interesting to see whether concurrent consumption of different chronobiotic agents additively boosts circadian phase shifts.

\section{THE FUTURE}

We have mentioned several ideas for future studies, and we will end by focusing on additional research avenues that may be worth exploring with respect to improving the health of shift workers.

\section{Using Novel Technologies to Better Personalise Guidance for Shift Workers}

Rapid recent advances in the development and uptake of digital technologies such as smartphones, apps, wearables, and artificial intelligence provide scientists with an unprecedented ability to comprehensively assess people's behaviours and health in freeliving contexts. The myCircadianClock app is a salient example of such technology. This app has already been used in multiple studies to monitor the circadian phenotypes of study participants, unveiling interesting insights into the effects of interventions such as TRE on human health $(64,117)$.

As data collected from digital devices are time-stamped, it is easier than ever to temporally map behavioural patterns and their biological sequelae, which could provide novel insights into the causes of changes in the health trajectories of shift workers. One could identify the hours of the day in which it is most frequently a shift worker's biological daytime by longitudinally assessing the timing of the individual's biological clock. As it is not currently practical to assess an individual's melatonin rhythm on a daily basis, the integration of data from surrogate markers of circadian phase such as body temperature and sleep/wake cycles could be used to approximate the timing of the biological daytime. These cycles could be monitored ambiently using data from devices such as smartphones, and the data from the devices could then be used to inform individual shift workers about how to best implement TRE. Where feasible, this process could be refined 


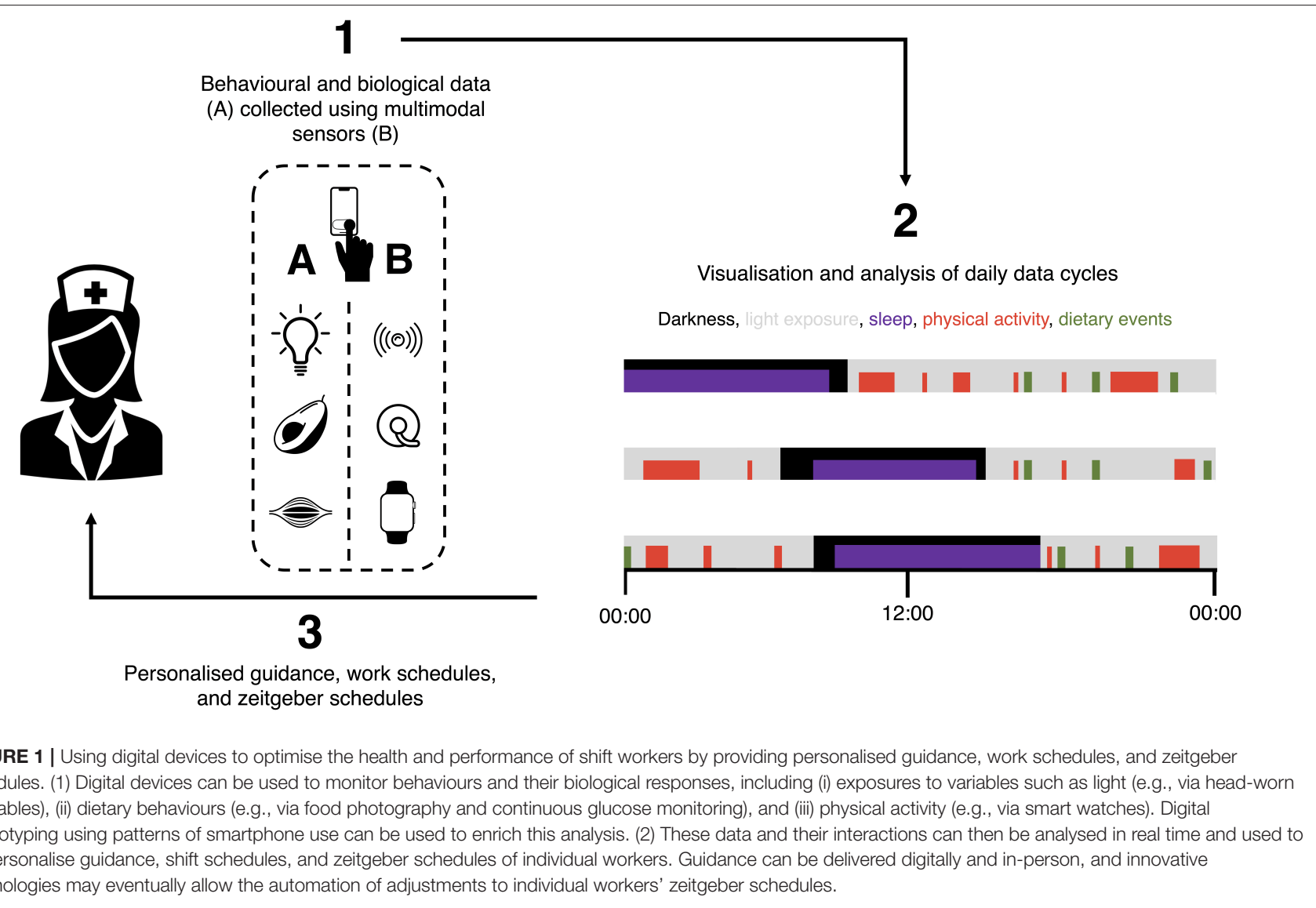

with the addition of round-the-clock measures of metabolic regulation, such as continuous glucose monitoring.

At a small scale, the feasibility of this type of approach has already been shown (118). Ultimately, implementing such methods at a large scale and including both shift workers and non-shift-working controls may help develop models that forecast transitions in the health of shift workers, as well as how to alter these trajectories. However, the data collection process will need to be relatively frictionless (for participants, at least) to achieve this. This will be facilitated by close collaboration between scientists and workers in the technology sector. With accurate monitoring in place, digital tools could then be implemented to improve the health and productivity of shift workers by optimising variables such as zeitgeber schedules in real time (Figure 1).

Innovative technologies could also provide novel means of generating insightful data while minimising participant burden. For example, sensors commonly built into smartphones can now be used to monitor blood parameters such as haemoglobin that once required invasive testing (119). Smartphones can also be used to monitor some exposures that are particularly relevant to shift workers, such as patterns of locomotion and exposure to light. One problem, however, is that it would be especially useful to assess exposure to light at the level of the eye. This requires new wearable devices, for smartphones are not suited to this, and many existing wearables that measure light exposure are frequently obstructed by clothing, confounding their data. It is possible to make smart eyewear to estimate retinal light exposure, and such eyewear may be especially useful for another purpose. The utility of all of these monitoring technologies may be enhanced by the addition of the ability to digitally "envirotype" individuals, ambiently tracking information about their environments to better understand the interaction between environment and phenotype (120). Building camera technology into eyewear is one way to accomplish this.

Meanwhile, digital phenotyping - assessing changes in people's phenotypes using data from digital devices - has already been used to identify patients' disease trajectories in neurological disorders such as schizophrenia (121). Such phenotyping can proceed without active user engagement, and it can also be used to assess behaviours such as sleep (122). Ultimately, use of multimodal novel sensors that analyse biofluids including interstitial fluid (e.g., continuous glucose monitoring), saliva, sweat, and tears may prove particularly useful in monitoring variables such as dietary intakes and associated changes in metabolites (123). However, the development of these sensors poses substantial challenges related to biofouling, accuracy, power, usability, calibration, and data security. 
These tools are promising approaches to forecasting changes in behaviours and health, and we hope they will help healthcare professionals intervene before individuals succumb to disease. We foresee that using sophisticated computational methods such as deep learning to concurrently analyse individuals' behavioural, health, and environmental data from multimodal sources will eventually enhance personalisation of guidance for individual shift workers (124).

\section{Applying Behavioural Science to Support Better Health Decisions by Shift Workers}

Even if shift workers understand precisely which behaviours they should enact to improve their health, they are prone to a variety of factors that impair decision making, such as circadian system misalignment and sleep loss $(125,126)$. Furthermore, knowledge alone is rarely sufficient to support lasting health behaviour change (127). It is therefore imperative to support the ability of these people to make smart decisions, and this requires applying principles from behavioural science, particularly at the level of the organisations that employ shift workers.

Significantly, many new technologies are strikingly habitforming, and this exemplifies the power of applying behavioural science principles to shape behaviour. If scientists and technologists can collaborate to effectively use behavioural science to create engaging, scalable products that deliver tailored health guidance to shift workers, all would benefit. We believe that technologies that deliver adaptive interventions to both help people avoid poor health decisions during states of vulnerability and support good health decisions during states of opportunity will be particularly advantageous (128).

The built environment also affects health in numerous ways (129), and given that shift workers are prone to health problems, it is particularly critical to pay attention to optimising the workplaces of these people. As shift workers commonly experience circadian system disruption and do not gain tolerance to such disruption (130), it may be valuable to create workplaces that allow close control over exposure to light, and intelligent use of "smart" lighting systems may benefit these individuals. We also anticipate the development of closed-loop devices that will personalise light exposure at the level of the individual.

The built environment influences physical activity. To support job performance and health, workplaces should have designated exercise spaces to encourage physical activity. Environmental design is relevant to nutrition too. Dietary choices depend strongly on where foods and drinks are sourced from. In work settings such as airplanes, food is provided for shift workers. However, most shift workers are left to source their own food, and when short on time many shift workers buy foods and drinks from vending machines (42). It is encouraging that many workers do select healthier dietary choices when they are available in vending machines, providing an opportunity for organisations to positively affect their employees' health decisions (131). Furthermore, workplace interventions to promote healthier diets, such as offering free fruit and labelling meals, have sometimes been shown to facilitate healthy dietary choices (132, 133). Simple changes in the placement of food in eating areas affect food selection too (134), and these changes can be leveraged to support the health of shift workers. Similarly, if workers are using products such as melatonin supplements and blue-light-blocking glasses to shift the phases of their circadian systems, it makes sense to help them acquire efficacious products.

It is also clear that social life is a strong influence on many shift workers' health behaviours, including their diets. The dietary attitudes and preferences of co-workers affect some workers' dietary choices (135), so group commitment to healthier dietary choices may aid the adoption of more nutritious diets. As stress strongly affects dietary choices in many people and shift workers often report high stress and abnormal dietary behaviours (136), interventions to nurture the resilience of shift workers and to improve workers' self-regulation skills may support their dietary choices. Such interventions include mindfulnessbased approaches (137). Shift workers could also benefit from other types of social support, including provision of additional childcare, as well as groups and events designed to minimise conflicts between their work and non-work activities.

Educating shift workers about how to sleep better is likely to be pivotal to their well-being, and shift work workplaces should have spaces for sleepy workers to nap. It is of course important to identify workers who have sleep disorders too, and simple screening tools such as brief questionnaires can be used for this (138). It may too be useful to screen for people who are simply not suited to certain shift schedules, for people differ substantially in how they tolerate shift work. Certain characteristics associate with better shift work tolerance, including robust general health; young age; male sex; not having children; low languidity and neuroticism; high extraversion, flexibility in sleeping habits, and internal locus of control; and a chronotype that is neither very early nor very late (18). Promisingly, personalising shift work schedules by removing night shifts for early chronotypes and excluding morning shifts for late chronotypes has been shown to prolong selfreported sleep, improve subjective sleep quality, and enhance worker well-being (139). To estimate chronotype, a study by Vetter and colleagues used a shift work-specific version of the Munich Chronotype Questionnaire (140), and this approach may be useful to help personalise work schedules for shift workers. Nonetheless, it would be useful to develop additional questionnaires designed specifically to identify appropriate shift schedules, as well as to track how workers respond to these schedules.

Finally, it is worth noting that many workplace wellness programmes that have been tested have not yielded impressive results (141). Assessing the effects of workplace interventions is difficult for numerous reasons, not the least of which are enforcing blinding and randomisation of participants. To date, marked heterogeneity between studies has made it challenging to assess the utility of workplace interventions for shift workers (30). And as is so often the case, the participants included in many of these studies did not comprise a diversity of ages and races, nor did the scientists attempt to define determinants of which workers responded positively to the interventions. None of this means that it is not possible to implement effective programmes, however, and we hope that lacklustre 
results to date do not stymie continued efforts to improve on workplace interventions by better incorporating principles from behavioural science.

\section{Using Alternatives to Traditional Study Designs to Better Personalise Guidance for Shift Workers}

To assess the efficacy of interventions to improve shift-worker health, it may make sense to use alternatives to many of the hitherto-used study designs. Recently, studies applying "Big Data" approaches have contributed to some advances in efforts to personalise medicine. However, it may be advantageous to concurrently carry out studies that use a "Small Data" paradigm for example, using $n$-of- 1 approaches to more rapidly assess how individual workers are responding to a given intervention and to forecast which of them are at risk of health trajectory transitions towards disease (142).

\section{CONCLUSIONS}

A large proportion of the workforce works shifts, and these individuals are integral to sustaining functional societies. However, the study of how to support the long-term health and well-being of these people has been somewhat neglected, and

\section{REFERENCES}

1. Wright KP Jr, McHill AW, Birks BR, Griffin BR, Rusterholz T, Chinoy ED. Entrainment of the human circadian clock to the natural light-dark cycle. Curr Biol. (2013) 23:1554-8. doi: 10.1016/j.cub.2013.06.039

2. Stothard ER, McHill AW, Depner CM, Birks BR, Moehlman TM, Ritchie HK, et al. Circadian entrainment to the natural light-dark cycle across seasons and the weekend. Curr Biol. (2017) 27:50813. doi: $10.1016 /$ j.cub.2016.12.041

3. IARC. IARC Working Group on the Evaluation of Carcinogenic Risk to Humans. Painting, Firefighting, and Shiftwork. (2010) Available online at: https://www.ncbi.nlm.nih.gov/books/NBK326814/ (accessed May 23, 2020).

4. Wagstaff AS, Sigstad Lie JA. Shift and night work and long working hoursa systematic review of safety implications. Scand J Work Environ Health. (2011) 37:173-85. doi: 10.5271/sjweh.3146

5. Kecklund G, Axelsson J. Health consequences of shift work and insufficient sleep. BMJ. (2016) 355:i5210. doi: 10.1136/bmj.i5210

6. Schernhammer ES, Lassen CF, Kenborg L, Ritz B, Olsen JH, Hansen J. Occupational history of night shift work and parkinson's disease in Denmark. Scand J Work Environ Health. (2015) 41:377-83. doi: 10.5271/sjwe h.3502

7. Jorgensen JT, Karlsen S, Stayner L, Andersen J, Andersen ZJ. Shift work and overall and cause-specific mortality in the danish nurse cohort. Scand J Work Environ Health. (2017) 43:117-26. doi: 10.5271/sjweh.3612

8. Musiek ES, Holtzman DM. Mechanisms linking circadian clocks, sleep, and neurodegeneration. Science. (2016) 354:10048. doi: $10.1126 /$ science.aah4968

9. Neto MLR, Almeida HG, Esmeraldo JD, Nobre CB, Pinheiro WR, de Oliveira CRT, et al. When health professionals look death in the eye: the mental health of professionals who deal daily with the 2019 coronavirus outbreak. Psychiatr Res. (2020) 288:112972. doi: 10.1016/j.psychres.2020. 112972

10. Richardson S, Hirsch JS, Narasimhan M, Crawford JM, McGinn T, Davidson KW, et al. Presenting characteristics, comorbidities, and outcomes among a relatively small proportion of relevant studies has included shift workers as participants. While the type of personalised interventions to support shift workers that we have discussed in this article are bound to produce logistical headaches for employers, the onus should be on supporting the long-term the health and performance of their employees. The acute difficulties arising from implementing customised shift schedule systems and suchlike may be more than made up for by the lasting benefits of these systems on health, safety, and productivity. We note also that as shift work increases the likelihood of adverse pregnancy outcomes and may lead to epigenetic modifications in parents that could plausibly affect the epigenetics and hence health of their children, supporting the health of shift workers could one day have critical effects on the well-being of future generations $(143,144)$.

Scientists now have an unprecedented ability to identify ways of helping shift workers. We hope that this ability is realised in the near future.

\section{AUTHOR CONTRIBUTIONS}

GP conceived the idea and drafted the manuscript. TW edited the manuscript and produced the final draft. All authors approved the final version and performed the literature review.
5700 patients hospitalized with COVID-19 in the New York city area. JAMA. (2020) 323:2052-9. doi: 10.1001/jama.2020.6775

11. ONS. Deaths Involving COVID-19, England and Wales: Deaths Occurring in March 2020. (2020). Available online at: https://www.ons. gov.uk/peoplepopulationandcommunity/birthsdeathsandmarriages/ deaths/bulletins/deathsinvolvingcovid19englandandwales/ deathsoccurringinmarch2020 (accessed May 23, 2020).

12. Hui DS, Azhar EI, Kim Y-J, Memish ZA, Oh M-D, Zumla A. Middle east respiratory syndrome coronavirus: risk factors and determinants of primary, household, and nosocomial transmission. Lancet Infect Dis. (2018) 18:e217-27. doi: 10.1016/S1473-3099(18)30127-0

13. Matsuyama R, Nishiura H, Kutsuna S, Hayakawa K, Ohmagari N. Clinical determinants of the severity of middle east respiratory syndrome (MERS): a systematic review and meta-analysis. BMC Public Health. (2016) 16:1203. doi: 10.1186/s12889-016-3881-4

14. Chan JWM, Ng CK, Chan YH, Mok TYW, Lee S, Chu SYY, et al. Short term outcome and risk factors for adverse clinical outcomes in adults with severe acute respiratory syndrome (SARS). Thorax. (2003) 58:6869. doi: $10.1136 /$ thorax.58.8.686

15. Lam CWK, Chan MHM, Wong CK. Severe acute respiratory syndrome: clinical and laboratory manifestations. Clin Biochem Rev. (2004) 25:121-32.

16. Louie JK, Acosta M, Samuel MC, Schechter R, Vugia DJ, Harriman K, et al. A novel risk factor for a novel virus: obesity and 2009 pandemic influenza A (H1N1). Clin Infect Dis. (2011) 52:301-12. doi: 10.1093/cid/ ciq152

17. Brandsaeter BJ, Pillgram M, Berild D, Kjekshus H, Kran AM, Bergersen BM. Hospitalised patients with suspected (2009). H1N1 influenza A in a hospital in Norway, july - december 2009. BMC Infect Dis. (2011) 11:75. doi: 10.1186/1471-2334-11-75

18. Ritonja J, Aronson KJ, Matthews RW, Boivin DB, Kantermann T. Working time society consensus statements: individual differences in shift work tolerance and recommendations for research and practice. Ind Health. (2019) 57:201-12. doi: 10.2486/indhealth.SW-5

19. Vetter C. Circadian disruption: what do we actually mean? Eur J Neurosci. (2018) 51:531-50. doi: 10.1111/ejn.14255 
20. Roenneberg T, Kuehnle T, Juda M, Kantermann T, Allebrandt K, Gordijn M, et al. Epidemiology of the human circadian clock. Sleep Med Rev. (2007) 11:429-38. doi: 10.1016/j.smrv.2007.07.005

21. Vetter C, Devore EE, Ramin CA, Speizer FE, Willett WC, Schernhammer ES. Mismatch of sleep and work timing and risk of type 2 diabetes. Diabetes Care. (2015) 38:1707-13. doi: 10.2337/dc15-0302

22. Leung L, Grundy A, Siemiatycki J, Arseneau J, Gilbert L, Gotlieb WH, et al. Shift work patterns, chronotype, and epithelial ovarian cancer risk. Cancer Epidemiol Biomark Prev. (2019) 28:987-95. doi: 10.1158/1055-9965.EPI-18-1112

23. van de Ven HA, van der Klink JJ, Vetter C, Roenneberg $T$, Gordijn M, Koolhaas W, et al. Sleep and need for recovery in shift workers: do chronotype and age matter? Ergonomics. (2016) 59:310-24. doi: 10.1080/00140139.2015.1058426

24. Razavi P, Devore EE, Bajaj A, Lockley SW, Figueiro MG, Ricchiuti V, et al. Shift work, chronotype, and melatonin rhythm in nurses. Cancer Epidemiol Biomark Prev. (2019) 28:1177-86. doi: 10.1158/1055-9965.EPI-18-1018

25. Roenneberg T, Merrow M. The circadian clock and human health. Curr Biol. (2016) 26:R432-43. doi: 10.1016/j.cub.2016.04.011

26. Grandner MA. Sleep, health, and society. Sleep Med Clin. (2017) 12:122. doi: 10.1016/j.jsmc.2016.10.012

27. Czeisler CA, Duffy JF, Shanahan TL, Brown EN, Mitchell JF, Rimmer DW, et al. Stability, precision, and near-24-hour period of the human circadian pacemaker. Science. (1999) 284:2177-81. doi: 10.1126/science.284.5423.2177

28. Golombek DA, Rosenstein RE. Physiology of circadian entrainment. Physiol Rev. (2010) 90:1063-102. doi: 10.1152/physrev.00009.2009

29. Wright HR, Lack LC. Effect of light wavelength on suppression and phase delay of the melatonin rhythm. Chronobiol Int. (2001) 18:8018. doi: 10.1081/CBI-100107515

30. Neil-Sztramko SE, Pahwa M, Demers PA, Gotay CC. Health-related interventions among night shift workers: a critical review of the literature. Scand J Work Environ Health. (2014) 40:543-56. doi: 10.5271/sjweh.3445

31. Phillips AJK, Vidafar P, Burns AC, McGlashan EM, Anderson C, Rajaratnam SMW, et al. High sensitivity and interindividual variability in the response of the human circadian system to evening light. Proc Natl Acad Sci USA. (2019) 116:12019-24. doi: 10.1073/pnas.1901824116

32. Zawilska JB, Skene DJ, Arendt J. Physiology and pharmacology of melatonin in relation to biological rhythms. Pharmacol Rep. (2009) 61:383410. doi: 10.1016/S1734-1140(09)70081-7

33. Wirz-Justice A, Krauchi K, Cajochen C, Danilenko KV, Renz C, Weber JM. Evening melatonin and bright light administration induce additive phase shifts in dim light melatonin onset. J Pineal Res. (2004) 36:1924. doi: 10.1111/j.1600-079X.2004.00117.x

34. Eastman CI, Hoese EK, Youngstedt SD, Liu L. Phase-shifting human circadian rhythms with exercise during the night shift. Physiol Behav. (1995) 58:1287-91. doi: 10.1016/0031-9384(95)02031-4

35. Youngstedt SD, Elliott JA, Kripke DF. Human circadian phase-response curves for exercise. J Physiol. (2019) 597:2253-68. doi: 10.1113/JP276943

36. Youngstedt SD, Kline CE, Elliott JA, Zielinski MR, Devlin TM, Moore TA. Circadian phase-shifting effects of bright light, exercise, and bright light + exercise. J Circadian Rhythms. (2016) 14:2. doi: 10.5334/jcr.137

37. Richter CP. A Behavioristic Study of the Activity of the Rat. Baltimore, MD: Williams and Wilkins Company (1922). doi: 10.5962/bhl.title. 151527

38. Damiola F, Le Minh N, Preitner N, Kornmann B, Fleury-Olela F, Schibler U. Restricted feeding uncouples circadian oscillators in peripheral tissues from the central pacemaker in the suprachiasmatic nucleus. Genes Dev. (2000) 14:2950-61. doi: 10.1101/gad.183500

39. Wehrens SMT, Christou S, Isherwood C, Middleton B, Gibbs MA, Archer $\mathrm{SN}$, et al. Meal timing regulates the human circadian system. Curr Biol. (2017) 27:1768-75.e3. doi: 10.1016/j.cub.2017.04.059

40. Lewis P, Oster H, Korf HW, Foster RG, Erren TC. Food as a circadian time cue - evidence from human studies. Nat Rev Endocrinol. (2020) 16:21323. doi: 10.1038/s41574-020-0318-z

41. Duffy JF, Kronauer RE, Czeisler CA. Phase-shifting human circadian rhythms: influence of sleep timing, social contact and light exposure. J Physiol. (1996) 495:289-97. doi: 10.1113/jphysiol.1996.sp0 21593
42. Gupta CC, Coates AM, Dorrian J, Banks S. The factors influencing the eating behaviour of shiftworkers: what, when, where and why. Ind Health. (2019) 57:419-53. doi: 10.2486/indhealth.2018-0147

43. Phillips SM, Chevalier S, Leidy HJ. Protein "requirements" beyond the RDA: implications for optimizing health. Appl Physiol Nutr Metab. (2016) 41:565-72. doi: 10.1139/apnm-2015-0550

44. McLellan TM, Caldwell JA, Lieberman HR. A review of caffeine's effects on cognitive, physical and occupational performance. Neurosci Biobehav Rev. (2016) 71:294-312. doi: 10.1016/j.neubiorev.2016.09.001

45. Syed SA, Kamimori GH, Kelly W, Eddington ND. Multiple dose pharmacokinetics of caffeine administered in chewing gum to normal healthy volunteers. Biopharm Drug Dispos. (2005) 26:403-9. doi: 10.1002/bdd.469

46. Kamimori GH, Karyekar CS, Otterstetter R, Cox DS, Balkin TJ, Belenky GL, et al. The rate of absorption and relative bioavailability of caffeine administered in chewing gum versus capsules to normal healthy volunteers. Int J Pharm. (2002) 234:159-67. doi: 10.1016/S0378-5173010 0958-9

47. Drake C, Roehrs T, Shambroom J, Roth T. Caffeine effects on sleep taken 0, 3, or 6 hours before going to bed. J Clin Sleep Med. (2013) 9:1195200. doi: $10.5664 /$ jcsm. 3170

48. Oike H, Sakurai M, Ippoushi K, Kobori M. Time-fixed feeding prevents obesity induced by chronic advances of light/dark cycles in mouse models of jet-lag/shift work. Biochem Biophys Res Commun. (2015) 465:55661. doi: 10.1016/j.bbrc.2015.08.059

49. Schilperoort M, van den Berg R, Dolle MET, van Oostrom CTM, Wagner K, Tambyrajah LL, et al. Time-restricted feeding improves adaptation to chronically alternating light-dark cycles. Sci Rep. (2019) 9:7874. doi: 10.1038/s41598-019-44398-7

50. Grant CL, Coates AM, Dorrian J, Kennaway DJ, Wittert GA, Heilbronn LK, et al. Timing of food intake during simulated night shift impacts glucose metabolism: a controlled study. Chronobiol Int. (2017) 34:100313. doi: $10.1080 / 07420528.2017 .1335318$

51. Grant CL, Dorrian J, Coates AM, Pajcin M, Kennaway DJ, Wittert GA, et al. The impact of meal timing on performance, sleepiness, gastric upset, and hunger during simulated night shift. Ind Health. (2017) 55:42336. doi: 10.2486/indhealth.2017-0047

52. Flanagan A, Lowson E, Arber S, Griffin BA, Skene DJ. Dietary patterns of nurses on rotational shifts are marked by redistribution of energy into the nightshift. Nutrients. (2020) 12:1053. doi: 10.3390/nu120 41053

53. Takagi H, Hari Y, Nakashima K, Kuno T, Ando T. Meta-analysis of relation of skipping breakfast with heart disease. Am J Cardiol. (2019) 124:978-86.

54. Ballon A, Neuenschwander M, Schlesinger S. Breakfast skipping is associated with increased risk of type 2 diabetes among adults: a systematic review and meta-analysis of prospective cohort studies. J Nutr. (2019) 149:10613. doi: $10.1093 /$ jn/nxy194

55. Betts JA, Chowdhury EA, Gonzalez JT, Richardson JD, Tsintzas K, Thompson D. Is breakfast the most important meal of the day? Proc Nutr Soc. (2016) 75:464-74. doi: 10.1017/S0029665116000318

56. Betts JA, Richardson JD, Chowdhury EA, Holman GD, Tsintzas K, Thompson D. The causal role of breakfast in energy balance and health: a randomized controlled trial in lean adults. Am J Clin Nutr. (2014) 100:53947. doi: 10.3945/ajcn.114.083402

57. Chowdhury EA, Richardson JD, Holman GD, Tsintzas K, Thompson D, Betts JA. The causal role of breakfast in energy balance and health: a randomized controlled trial in obese adults. Am J Clin Nutr. (2016) 103:74756. doi: 10.3945/ajcn.115.122044

58. Sutton EF, Beyl R, Early KS, Cefalu WT, Ravussin E, Peterson CM. Early time-restricted feeding improves insulin sensitivity, blood pressure, and oxidative stress even without weight loss in men with prediabetes. Cell Metab. (2018) 27:1212-21.e3. doi: 10.1016/j.cmet.2018. 04.010

59. Jamshed H, Beyl RA, Della Manna DL, Yang ES, Ravussin E, Peterson CM. Early time-restricted feeding improves 24-hour glucose levels and affects markers of the circadian clock, aging, and autophagy in humans. Nutrients. (2019) 11:1234. doi: 10.3390/nu11061234 
60. Ravussin E, Beyl RA, Poggiogalle E, Hsia DS, Peterson CM. Early timerestricted feeding reduces appetite and increases fat oxidation but does not affect energy expenditure in humans. Obesity (Silver Spring). (2019) 27:1244-54. doi: 10.1002/oby.22518

61. Hutchison AT, Regmi P, Manoogian ENC, Fleischer JG, Wittert GA, Panda $S$, et al. Time-restricted feeding improves glucose tolerance in men at risk for type 2 diabetes: a randomized crossover trial. Obesity (Silver Spring). (2019) 27:724-32. doi: 10.1002/oby.22449

62. Antoni R, Robertson TM, Robertson MD, Johnston JD. A pilot feasibility study exploring the effects of a moderate time-restricted feeding intervention on energy intake, adiposity and metabolic physiology in free-living human subjects. J Nutr Sci. (2018) 7:e22. doi: 10.1017/jns.2018.13

63. Parr EB, Devlin BL, Radford BE, Hawley JA. A delayed morning and earlier evening time-restricted feeding protocol for improving glycemic control and dietary adherence in men with overweight/obesity: a randomized controlled trial. Nutrients. (2020) 12:505. doi: 10.3390/nu12020505

64. Wilkinson MJ, Manoogian ENC, Zadourian A, Lo H, Fakhouri S, Shoghi A, et al. Ten-hour time-restricted eating reduces weight, blood pressure, and atherogenic lipids in patients with metabolic syndrome. Cell metabolism. (2020) 31:92-104.e5. doi: 10.1016/j.cmet.2019.11.004

65. Alhussain MH, Macdonald IA, Taylor MA. Irregular meal-pattern effects on energy expenditure, metabolism, and appetite regulation: a randomized controlled trial in healthy normal-weight women. Am J Clin Nutr. (2016) 104:21-32. doi: 10.3945/ajcn.115.125401

66. Jakubowicz D, Barnea M, Wainstein J, Froy O. High caloric intake at breakfast vs. dinner differentially influences weight loss of overweight and obese women. Obesity. (2013) 21:2504-12. doi: 10.1002/oby.20460

67. Jakubowicz D, Landau Z, Tsameret S, Wainstein J, Raz I, Ahren B, et al. Reduction in glycated hemoglobin and daily insulin dose alongside circadian clock upregulation in patients with type 2 diabetes consuming a three-meal diet: a randomized clinical trial. Diabetes Care. (2019) 42:217180. doi: $10.2337 / \mathrm{dc} 19-1142$

68. Kessler K, Hornemann S, Petzke KJ, Kemper M, Kramer A, Pfeiffer AF, et al. The effect of diurnal distribution of carbohydrates and fat on glycaemic control in humans: a randomized controlled trial. Sci Rep. (2017) 7:44170. doi: 10.1038/srep44170

69. Sylow L, Kleinert M, Richter EA, Jensen TE. Exercise-stimulated glucose uptake - regulation and implications for glycaemic control. Nat Rev Endocrinol. (2017) 13:133-48. doi: 10.1038/nrendo.2016.162

70. Areta JL, Burke LM, Ross ML, Camera DM, West DW, Broad EM, et al. Timing and distribution of protein ingestion during prolonged recovery from resistance exercise alters myofibrillar protein synthesis. J Physiol. (2013) 591:2319-31. doi: 10.1113/jphysiol.2012.244897

71. Shukla AP, Dickison M, Coughlin N, Karan A, Mauer E, Truong W, et al. The impact of food order on postprandial glycaemic excursions in prediabetes. Diabetes Obes Metab. (2019) 21:377-81. doi: 10.1111/dom. 13503

72. Shukla AP, Iliescu RG, Thomas CE, Aronne LJ. Food order has a significant impact on postprandial glucose and insulin levels. Diabetes Care. (2015) 38:e98-9. doi: 10.2337/dc15-0429

73. Shukla AP, Andono J, Touhamy SH, Casper A, Iliescu RG, Mauer E, et al. Carbohydrate-last meal pattern lowers postprandial glucose and insulin excursions in type 2 diabetes. BMJ Open Diabetes Res Care. (2017) 5:e000440. doi: 10.1136/bmjdrc-2017-000440

74. Panda S. Circadian physiology of metabolism. Science. (2016) 354:100815. doi: 10.1126/science.aah4967

75. Gupta CC, Centofanti S, Dorrian J, Coates A, Stepien JM, Kennaway D, et al. Altering meal timing to improve cognitive performance during simulated nightshifts. Chronobiol Int. (2019) 36:1691-713. doi: 10.1080/07420528.2019.1676256

76. Gupta CC, Centofanti S, Dorrian J, Coates AM, Stepien JM, Kennaway $\mathrm{D}$, et al. Subjective hunger, gastric upset, and sleepiness in response to altered meal timing during simulated shiftwork. Nutrients. (2019) 11:1352. doi: 10.3390/nu11061352

77. Centofanti S, Dorrian J, Hilditch C, Grant C, Coates A, Banks S. Eating on nightshift: A big vs small snack impairs glucose response to breakfast. Neurobiol Sleep Circadian Rhythms. (2018) 4:44-8. doi: 10.1016/j.nbscr.2017.12.001
78. Tognini P, Murakami M, Liu Y, Eckel-Mahan KL, Newman JC, Verdin E, et al. Distinct circadian signatures in liver and gut clocks revealed by ketogenic diet. Cell Metab. (2017) 26:523-38.e5. doi: 10.1016/j.cmet.2017. 08.015

79. Genzer Y, Dadon M, Burg C, Chapnik N, Froy O. Ketogenic diet delays the phase of circadian rhythms and does not affect AMP-activated protein kinase (AMPK) in mouse liver. Mol Cell Endocrinol. (2015) 417:12430. doi: 10.1016/j.mce.2015.09.012

80. Oishi K, Yamamoto S, Uchida D, Doi R. Ketogenic diet and fasting induce the expression of cold-inducible RNA-binding protein with timedependent hypothermia in the mouse liver. FEBS Open Bio. (2013) 3:1925. doi: 10.1016/j.fob.2013.03.005

81. Summa KC, Voigt RM, Forsyth CB, Shaikh M, Cavanaugh K, Tang Y, et al. Disruption of the circadian clock in mice increases intestinal permeability and promotes alcohol-induced hepatic pathology and inflammation. PLoS ONE. (2013) 8:e67102. doi: 10.1371/journal.pone.0067102

82. Ajala O, English P, Pinkney J. Systematic review and meta-analysis of different dietary approaches to the management of type 2 diabetes. Am J Clin Nutr. (2013) 97:505-16. doi: 10.3945/ajcn.112.042457

83. Akasaka T, Sueta D, Tabata N, Takashio S, Yamamoto E, Izumiya $\mathrm{Y}$, et al. Effects of the mean amplitude of glycemic excursions and vascular endothelial dysfunction on cardiovascular events in nondiabetic patients with coronary artery disease. J Am Heart Assoc. (2017) 6:e004841. doi: 10.1161/JAHA.116.004841

84. Buysschaert M, Medina JL, Bergman M, Shah A, Lonier J. Prediabetes and associated disorders. Endocrine. (2015) 48:371-93. doi: 10.1007/s12020-014-0436-2

85. Huang Y, Cai X, Chen P, Mai W, Tang H, Huang Y, et al. Associations of prediabetes with all-cause and cardiovascular mortality: a meta-analysis. Ann Med. (2014) 46:684-92. doi: 10.3109/07853890.2014.955051

86. Huang Y, Cai X, Qiu M, Chen P, Tang H, Hu Y, et al. Prediabetes and the risk of cancer: a meta-analysis. Diabetologia. (2014) 57:22619. doi: 10.1007/s00125-014-3361-2

87. Rawlings AM, Sharrett AR, Mosley TH, Ballew SH, Deal JA, Selvin E. Glucose peaks and the risk of dementia and 20-year cognitive decline. Diabetes Care. (2017) 40:879-86. doi: 10.2337/dc16-2203

88. Siegmann MJ, Athinarayanan SJ, Hallberg SJ, McKenzie AL, Bhanpuri $\mathrm{NH}$, Campbell WW, et al. Improvement in patient-reported sleep in type 2 diabetes and prediabetes participants receiving a continuous care intervention with nutritional ketosis. Sleep Med. (2019) 55:929. doi: 10.1016/j.sleep.2018.12.014

89. Newman JC, Verdin E. $\beta$-Hydroxybutyrate: a signaling metabolite. Ann Rev Nutr. (2017) 37:51-76. doi: 10.1146/annurev-nutr-071816-064916

90. Roberts MN, Wallace MA, Tomilov AA, Zhou Z, Marcotte GR, Tran D, et al. A ketogenic diet extends longevity and healthspan in adult mice. Cell Metab. (2018) 26:539-46.e5. doi: 10.1016/j.cmet.2018.04.005

91. Zhao M, Huang X, Cheng X, Lin X, Zhao T, Wu L, et al. Ketogenic diet improves the spatial memory impairment caused by exposure to hypobaric hypoxia through increased acetylation of histones in rats. PLoS ONE. (2017) 12:e174477. doi: 10.1371/journal.pone.0174477

92. Bokenberger K, Sjolander A, Dahl Aslan AK, Karlsson IK, Akerstedt T, Pedersen NL. Shift work and risk of incident dementia: a study of two population-based cohorts. Eur J Epidemiol. (2018) 33:97787. doi: 10.1007/s10654-018-0430-8

93. Nabe-Nielsen K, Hansen AM, Ishtiak-Ahmed K, Grynderup MB, Gyntelberg F, Islamoska S, et al. Night shift work, long working hours and dementia: a longitudinal study of the danish work environment cohort study. BMJ Open. (2019) 9:e027027. doi: 10.1136/bmjopen-2018-027027

94. Ribas-Latre A, Eckel-Mahan K. Interdependence of nutrient metabolism and the circadian clock system: importance for metabolic health. Mol Metab. (2016) 5:133-52. doi: 10.1016/j.molmet.2015.12.006

95. St-Onge MP, Mikic A, Pietrolungo CE. Effects of diet on sleep quality. $A d v$ Nutr. (2016) 7:938-49. doi: 10.3945/an.116.012336

96. Solt LA, Wang Y, Banerjee S, Hughes T, Kojetin DJ, Lundasen T, et al. Regulation of circadian behaviour and metabolism by synthetic REV-ERB agonists. Nature. (2012) 485:62-8. doi: 10.1038/nature11030

97. Ker K, Edwards PJ, Felix LM, Blackhall K, Roberts I. Caffeine for the prevention of injuries and errors in shift workers. Cochrane 
Database Syst Rev. (2010) 2010:Cd008508. doi: 10.1002/14651858.CD0 08508

98. Clark I, Landolt HP. Coffee, caffeine, and sleep: a systematic review of epidemiological studies and randomized controlled trials. Sleep Med Rev. (2017) 31:70-8. doi: 10.1016/j.smrv.2016.01.006

99. Burke TM, Markwald RR, McHill AW, Chinoy ED, Snider JA, Bessman SC, et al. Effects of caffeine on the human circadian clock in vivo and in vitro. Sci Transl Med. (2015) 7:305ra146. doi: 10.1126/scitranslmed.aac5125

100. Dworak M, Kim T, McCarley RW, Basheer R. Creatine supplementation reduces sleep need and homeostatic sleep pressure in rats. J Sleep Res. (2017) 26:377-85. doi: 10.1111/jsr.12523

101. Kreider RB, Kalman DS, Antonio J, Ziegenfuss TN, Wildman R, Collins R, et al. International society of sports nutrition position stand: safety and efficacy of creatine supplementation in exercise, sport, and medicine. J Int Soc Sports Nutr. (2017) 14:18. doi: 10.1186/s12970-017-0173-Z

102. McMorris T, Harris RC, Howard AN, Langridge G, Hall B, Corbett J, et al. Creatine supplementation, sleep deprivation, cortisol, melatonin and behavior. Physiol Behav. (2007) 90:21-8. doi: 10.1016/j.physbeh.2006.08.024

103. McMorris T, Harris RC, Swain J, Corbett J, Collard K, Dyson RJ, et al. Effect of creatine supplementation and sleep deprivation, with mild exercise, on cognitive and psychomotor performance, mood state, and plasma concentrations of catecholamines and cortisol. Psychopharmacol. (2006) 185:93-103. doi: 10.1007/s00213-005-0269-z

104. Cook CJ, Crewther BT, Kilduff LP, Drawer S, Gaviglio CM. Skill execution and sleep deprivation: effects of acute caffeine or creatine supplementation - a randomized placebo-controlled trial. J Int Soc Sports Nutr. (2011) 8:2. doi: 10.1186/1550-2783-8-2

105. Trexler ET, Smith-Ryan AE. Creatine and caffeine: considerations for concurrent supplementation. Int J Sport Nutr Exerc Metab. (2015) 25:60723. doi: 10.1123/ijsnem.2014-0193

106. Cubero J, Valero V, Sánchez J, Rivero M, Parvez H, Rodríguez AB, et al. The circadian rhythm of tryptophan in breast milk affects the rhythms of 6-sulfatoxymelatonin and sleep in newborn. Neuro Endocrinol Lett. (2005) 26:657-61.

107. Cubero J, Narciso D, Aparicio S, Garau C, Valero V, Rivero M, et al. Improved circadian sleep-wake cycle in infants fed a day/night dissociated formula milk. Neuro Endocrinol Lett. (2006) 27:373-80.

108. Silber BY, Schmitt JA. Effects of tryptophan loading on human cognition, mood, and sleep. Neurosci Biobehav Rev. (2010) 34:387-407. doi: 10.1016/j.neubiorev.2009.08.005

109. Yasuo S, Iwamoto A, Lee SI, Ochiai S, Hitachi R, Shibata S, et al. 1-Serine enhances light-induced circadian phase resetting in mice and humans. $J$ Nutr. (2017) 147:2347-55. doi: 10.3945/jn.117.255380

110. Fukuda T, Haraguchi A, Takahashi M, Nakaoka T, Fukazawa M, Okubo J, et al. A randomized, double-blind and placebo-controlled crossover trial on the effect of l-ornithine ingestion on the human circadian clock. Chronobiol Int. (2018) 35:1445-55. doi: 10.1080/07420528.2018.14 90315

111. Horiuchi M, Kanesada H, Miyata T, Watanabe K, Nishimura A, Kokubo $\mathrm{T}$, et al. Ornithine ingestion improved sleep disturbances but was not associated with correction of blood tryptophan ratio in Japanese antarctica expedition members during summer. Nutr Res. (2013) 33:55764. doi: 10.1016/j.nutres.2013.05.001

112. Miyake M, Kirisako T, Kokubo T, Miura Y, Morishita K, Okamura $\mathrm{H}$, et al. Randomised controlled trial of the effects of L-ornithine on stress markers and sleep quality in healthy workers. Nutr J. (2014) 13:53. doi: 10.1186/1475-2891-13-53

113. Yamadera W, Inagawa K, Chiba S, Bannai M, Takahashi M, Nakayama K. Glycine ingestion improves subjective sleep quality in human volunteers, correlating with polysomnographic changes. Sleep Biol Rhythms. (2007) 5:126-31. doi: 10.1111/j.1479-8425.2007.00262.x

114. Kawai N, Sakai N, Okuro M, Karakawa S, Tsuneyoshi Y, Kawasaki $\mathrm{N}$, et al. The sleep-promoting and hypothermic effects of glycine are mediated by NMDA receptors in the suprachiasmatic nucleus. Neuropsychopharmacology. (2015) 40:1405-16. doi: 10.1038/npp.20 14.326

115. Bannai M, Kawai N, Ono K, Nakahara K, Murakami N. The effects of glycine on subjective daytime performance in partially sleep-restricted healthy volunteers. Front Neurol. (2012) 3:61. doi: 10.3389/fneur.2012. 00061

116. Wang W, Wu Z, Dai Z, Yang Y, Wang J, Wu G. Glycine metabolism in animals and humans: implications for nutrition and health. Amino Acids. (2013) 45:463-77. doi: 10.1007/s00726-013-1493-1

117. Gill S, Panda S. A smartphone app reveals erratic diurnal eating patterns in humans that can be modulated for health benefits. Cell Metab. (2015) 22:789-98. doi: 10.1016/j.cmet.2015.09.005

118. Skarke C, Lahens NF, Rhoades SD, Campbell A, Bittinger K, Bailey A, et al. A pilot characterization of the human chronobiome. Sci Rep. (2017) 7:17141. doi: 10.1038/s41598-017-17362-6

119. Wang E, Zhu J, Li W, Rana R, Patel S. Noninvasive hemoglobin measurement using unmodified smartphone camera and white flash. In: 39th Annual International Conference of the IEEE Engineering in Medicine and Biology Society. Jeju Island, South Korea (2017). p. 23336. doi: 10.1109/EMBC.2017.8037323

120. Engelhard MM, Oliver JA, McClernon FJ. Digital envirotyping: quantifying environmental determinants of health and behavior. NPJ Digit Med. (2020) 3:36. doi: 10.1038/s41746-020-0245-3

121. Barnett I, Torous J, Staples P, Sandoval L, Keshavan M, Onnela JP. Relapse prediction in schizophrenia through digital phenotyping: a pilot study. Neuropsychopharmacology. (2018) 43:1660-6. doi: 10.1038/s41386-018-0030-z

122. Staples P, Torous J, Barnett I, Carlson K, Sandoval L, Keshavan M, et al. A comparison of passive and active estimates of sleep in a cohort with schizophrenia. NPJ Schizophr. (2017) 3:37. doi: 10.1038/s41537-017-0038-0

123. Kim J, Campbell AS, de Ávila BE, Wang J. Wearable biosensors for healthcare monitoring. Nat Biotechnol. (2019) 37:389406. doi: 10.1038/s41587-019-0045-y

124. Topol EJ. High-performance medicine: the convergence of human and artificial intelligence. Nat Med. (2019) 25:4456. doi: 10.1038/s41591-018-0300-7

125. Chellappa SL, Morris CJ, Scheer F. Effects of circadian misalignment on cognition in chronic shift workers. Sci Rep. (2019) 9:699. doi: 10.1038/s41598-018-36762-w

126. Krause AJ, Simon EB, Mander BA, Greer SM, Saletin JM, Goldstein-Piekarski AN, et al. The sleep-deprived human brain. Nat Rev Neurosci. (2017) 18:40418. doi: 10.1038/nrn.2017.55

127. Kelly MP, Barker M. Why is changing health-related behaviour so difficult? Public Health. (2016) 136:109-16. doi: 10.1016/j.puhe.2016.03.030

128. Nahum-Shani I, Smith SN, Spring BJ, Collins LM, Witkiewitz K, Tewari A, et al. Just-in-time adaptive interventions (JITAIs) in mobile health: key components and design principles for ongoing health behavior support. Ann Behav Med. (2018) 52:446-62. doi: 10.1007/s12160-016-9830-8

129. Jackson RJ, Dannenberg AL, Frumkin H. Health and the built environment: 10 years after. Am J Public Health. (2013) 103:1542-4. doi: 10.2105/AJPH.2013.301482

130. Morris CJ, Purvis TE, Mistretta J, Scheer FA. Effects of the internal circadian system and circadian misalignment on glucose tolerance in chronic shift workers. J Clin Endocrinol Metab. (2016) 101:106674. doi: 10.1210/jc.2015-3924

131. Lillehoj CJ, Nothwehr F, Shipley K, Voss C. Vending assessment and program implementation in four iowa worksites. Health Promot Pract. (2015) 16:81425. doi: 10.1177/1524839915596346

132. Alinia S, Lassen AD, Krogholm KS, Christensen T, Hels OH, Tetens I. A workplace feasibility study of the effect of a minimal fruit intervention on fruit intake. Public Health Nutr. (2011) 14:13827. doi: $10.1017 /$ S1368980010002569

133. Lassen AD, Beck A, Leedo E, Andersen EW, Christensen T, Mejborn H, et al. Effectiveness of offering healthy labelled meals in improving the nutritional quality of lunch meals eaten in a worksite canteen. Appetite. (2014) 75:128-34. doi: 10.1016/j.appet.2013.12.005

134. Bucher T, Collins C, Rollo ME, McCaffrey TA, De Vlieger N, Van der Bend D, et al. Nudging consumers towards healthier choices: a systematic review of positional influences on food choice. Br J Nutr. (2016) 115:225263. doi: 10.1017/S0007114516001653

135. Bonnell EK, Huggins CE, Huggins CT, McCaffrey TA, Palermo C, Bonham MP. Influences on dietary choices during day versus night 
shift in shift workers: a mixed methods study. Nutrients. (2017) 9:193. doi: 10.3390/nu9030193

136. Wong H, Wong MC, Wong SY, Lee A. The association between shift duty and abnormal eating behavior among nurses working in a major hospital: a cross-sectional study. Int J Nurs Stud. (2010) 47:10217. doi: 10.1016/j.ijnurstu.2010.01.001

137. Gauthier T, Meyer RM, Grefe D, Gold JI. An on-the-job mindfulnessbased intervention for pediatric ICU nurses: a pilot. J Pediatr Nurs. (2015) 30:402-9. doi: 10.1016/j.pedn.2014.10.005

138. Klingman KJ, Jungquist CR, Perlis ML. Questionnaires that screen for multiple sleep disorders. Sleep Med Rev. (2017) 32:37-44. doi: 10.1016/j.smrv.2016.02.004

139. Vetter C, Fischer D, Matera JL, Roenneberg T. Aligning work and circadian time in shift workers improves sleep and reduces circadian disruption. Curr Biol. (2015) 25:907-11. doi: 10.1016/j.cub.2015. 01.064

140. Juda M, Vetter C, Roenneberg T. The munich chronotype questionnaire for shift-workers (MCTQShift). J Biol Rhythms. (2013) 28:130-40. doi: 10.1177/0748730412475041

141. Song Z, Baicker K. Effect of a workplace wellness program on employee health and economic outcomes: a randomized clinical trial. JAMA. (2019) 321:1491-501. doi: 10.1001/jama.2019.3307
142. Hekler EB, Klasnja P, Chevance G, Golaszewski NM, Lewis D, Sim I. Why we need a small data paradigm. BMC Med. (2019) 17:133. doi: 10.1186/s12916-019-1366-x

143. Cai C, Vandermeer B, Khurana R, Nerenberg K, Featherstone R, Sebastianski $\mathrm{M}$, et al. The impact of occupational shift work and working hours during pregnancy on health outcomes: a systematic review and meta-analysis. Am J Obstet Gynecol. (2019) 221:563-76. doi: 10.1016/j.ajog.2019.06.051

144. Strohmaier S, Devore EE, Vetter C, Eliassen AH, Rosner B, Okereke OI, et al. Night shift work before and during pregnancy in relation to depression and anxiety in adolescent and young adult offspring. Eur J Epidemiol. (2019) 34:625-35. doi: 10.1007/s10654-019-00525-2

Conflict of Interest: The authors declare that the research was conducted in the absence of any commercial or financial relationships that could be construed as a potential conflict of interest.

Copyright (c) 2020 Potter and Wood. This is an open-access article distributed under the terms of the Creative Commons Attribution License (CC BY). The use, distribution or reproduction in other forums is permitted, provided the original author(s) and the copyright owner(s) are credited and that the original publication in this journal is cited, in accordance with accepted academic practice. No use, distribution or reproduction is permitted which does not comply with these terms. 